\title{
Investigation of the association of idiopathic male infertility with polymorphisms in the methionine synthase (MTR) gene
}

\author{
Asghar Tanoomand', Abolfazl Hajibemani' ${ }^{2}$, Beheshteh Abouhamzeh ${ }^{3}$ \\ 'Department of Basic Sciences, Faculty of Medicine, Maragheh University of Medical Sciences, Maragheh; ${ }^{2}$ Department of Clinical Sciences, Faculty of \\ Veterinary Medicine, University of Tabriz, Tabriz; ${ }^{3}$ Department of Anatomical Sciences, Faculty of Medicine, AJA University of Medical Sciences, Tehran, \\ Iran
}

Objective: Spermatogenesis is a complex process that is regulated by a number of genes, some of which are involved in folate-dependent 1-carbon metabolism. Methionine synthase (encoded by MTR) is a key enzyme participating in this pathway. This study aimed to investigate the relationship of the MTR $2756 \mathrm{~A}>\mathrm{G}$ polymorphism with idiopathic male fertility in the Iranian population.

Methods: The participants of this study included 100 men with idiopathic infertility and 100 healthy men as the control group. Genotyping of MTR 2756A $>G$ was performed using the polymerase chain reaction and restriction fragment length polymorphism technique. The obtained data were analyzed using SPSS ver. 20.0 with a level of confidence of $p<0.05$.

Results: The frequencies of the $A$ and $\mathrm{G}$ alleles at this locus were $77 \%$ and $23 \%$ in infertile patients and $84 \%$ and $16 \%$ in the control group, respectively. The frequencies of the GG, GA, and AA genotypes were $5 \%, 36 \%$, and $59 \%$ in the infertile patients versus $3 \%, 27 \%$, and $70 \%$ in the control group, respectively. No significant difference was observed in any genetic models.

Conclusion: In general, the findings of this study suggest that the MTR 2756A $>G$ single-nucleotide polymorphism is not a predisposing factor for idiopathic infertility in men.

Keywords: Idiopathic; Male infertility; MTR; Polymorphism

\section{Introduction}

Infertility is defined as a couple's failure to achieve clinical pregnancy after 1 year of regular unprotected sexual intercourse [1]. Infertility is a global problem with a major impact on quality of life. The rate of infertility varies across different areas [2], and it affects about $8 \%-$ $15 \%$ of couples all over the world. Approximately $40 \%$ of all infertility

Received: Nov 16, 2018 · Revised: May 15, 2019· Accepted: May 29, 2019 Corresponding author: Beheshteh Abouhamzeh

Department of Anatomical Sciences, Faculty of Medicine, AJA University of Medical Sciences, Fatemi, Sarhang Etemadzadeh, Tehran, Iran

Tel:+98-9122838964 Fax:+98-2188337919 E-mail: b.abouhamzeh.ba@gmail.com

*This work was supported by a grant from AJA University of Medical Sciences of Iran.

This is an Open Access article distributed under the terms of the Creative Commons Attribution Non-Commercial License (http://creativecommons.org/licenses/by-nc/4.0/) which permits unrestricted non-commercial use, distribution, and reproduction in any medium, provided the original work is properly cited. cases are related to male factors [3], of which $37 \%-58 \%$ are classified as idiopathic male infertility. Idiopathic male infertility may be caused by various factors, including chronic stress and endocrine disorders that result from environmental pollution, reactive oxygen species, and genetic abnormalities [4]. Spermatogenesis is a complex process that is regulated by multiple genes [5], some of which are involved in the folate-dependent 1-carbon metabolism pathway. This pathway includes the metabolism of homocysteine and folate [6]. Folate is necessary for thymidylate and purine biosynthesis and acts as a substrate for many biological reactions, such as 1-carbon-unit transfer, DNA synthesis, cell division and proliferation, the metabolism of several amino acids, transmethylation, and transsulfuration [7]. As such, this pathway plays a key role in DNA synthesis during the process of spermatogenesis. It has been shown that folate, homocysteine, and their derivatives are important factors in spermatogenesis [8]. Disor- 
ders of folate metabolism may lead to sperm DNA damage, which affects sperm quality, count, motility, and morphology [9]. The main enzymes of this pathway include 5,10-methylenetetrahydrofolate dehydrogenase (MTHFD), 5,10-methenyltetrahydrofolate cyclohydrolase, 10-formyltetrahydrofolate synthetase, serine hydroxymethyltransferase, and methionine synthase (MS; encoded by MTR) [10]. MS is a key enzyme participating in folate-dependent 1-carbon metabolism and DNA synthesis, methylation, and repair [1]. MS has four binding sites for cobalamin (vitamin $\mathrm{B}_{12}$ ), homocysteine, 5-methyltetrahydrofolate, and S-adenosyl methionine [2,3]. The gene that codes MS, MTR, is located at $1 \mathrm{q} 43$. MS is a vitamin $\mathrm{B}_{12}$-dependent enzyme that catalyzes the transfer of a methyl group from 5-methyltetrahydrofolate to homocysteine in order to produce methionine and tetrahydrofolate. Tetrahydrofolate is necessary for nucleotide synthesis, and methionine is required for the synthesis of S-adenosyl methionine and the transfer of a methyl group from S-adenosyl methionine to DNA [4]. In this pathway, 5- and 10-methyltetrahydrofolate participate in DNA synthesis through the replacement of dUTP with dTTP $[5,11]$. Mutations in the MTR gene result in a reduction of methylcobalamin levels, leading to homocystinuria, a condition characterized by increased homocysteine and decreased methionine levels in blood [6]. Various studies have shown a relationship between the $2756 \mathrm{~A}>\mathrm{G}$ polymorphism in the coding region of MTR and some disorders. It has been reported that the MTR $2756 \mathrm{~A}>\mathrm{G}$ polymorphism leads to the replacement of aspartic acid with glycerol [7,8]. Other studies have found a negative relationship between the GG genotype and homocysteine, suggesting increased enzyme activity at the time of the occurrence of the polymorphism in the MTR gene in sperm DNA [9]. Several studies have revealed a relationship between the MTR 2756A $>G$ polymorphism and the pathogenesis of Alzheimer disease, and associations with other disorders such as cancer, chromosomal disorders, Parkinson disease, and loss of pregnancy have also been investigated $[12,13]$. Very few studies have explored the possible association of the $2756 \mathrm{~A}>\mathrm{G}$ polymorphisms in the coding region of MTR with male infertility, and the existing studies on this topic have reported inconsistent results. Some studies have reported no relationship between the $2756 \mathrm{~A}>\mathrm{G}$ polymorphism in the MTR coding region and infertility caused by nonobstructive azoospermia [10,14], while in another study, a statistically significant relationship was found between the $2756 \mathrm{~A}>\mathrm{G}$ polymorphism in the MTR coding region and idiopathic infertility [15]. Since no study has yet been conducted of the MTR $2756 \mathrm{~A}>\mathrm{G}$ polymorphism in the coding region of the MTR gene and its relationship with idiopathic male infertility in the Iranian population, this study aimed to determine the prevalence of the MTR $2756 \mathrm{~A}>\mathrm{G}$ polymorphism and to investigate its relationship with idiopathic male fertility in this population.

\section{Methods}

\section{Study population}

The participants of this study included 200 men from the west and northwest of Iran, of whom 100 had idiopathic infertility and 100 were healthy men included as the control group. The men in the control group had previously fathered at least one healthy child. Informed written consent was obtained from all participants prior to enrollment in the study. The subjects' mean age was $35 \pm 5$ years (range, 20-48 years). The inclusion criteria for this study were idiopathic male infertility after at least 1 year of regular unprotected sexual intercourse (2-3 times a week), normal findings on a transvaginal ultrasound examination of their female partner, and no history of pelvic inflammatory disease or abdominal surgery. The exclusion criteria consisted of disorders such as prostatitis, urethritis, varicocele, diabetes, and parotiditis; chromosomal disorders; genital or urethral obstructive lesions; a history of cryptorchidism in childhood; and occupational risks.

\section{Sampling and data collection}

This case-control study was performed after receiving permission from the ethics committee of AJA University of Medical Sciences (IR,AJAUMS.REC. 1396.113). All participants underwent clinical and laboratory examinations, a physical examination, and a sperm analysis, which assessed number, motility, viability, and morphology in accordance with the World Health Organization guidelines [16]. From every individual in both groups, $2 \mathrm{~mL}$ of blood was collected in sterile tubes containing EDTA (EDTA K3E 15\%, 0.12 mL; BD Vacutainer, BD Vacutainer Systems, Plymouth, UK), and the blood samples were stored at $-20^{\circ} \mathrm{C}$ before DNA extraction.

\section{Primers}

Genotyping of the MTR polymorphism was performed using the polymerase chain reaction and restriction fragment length polymorphism (PCR-RFLP) technique. The sequences of the primer set used to identify different point mutations in the 2756 region of the MTR gene in each allele were as follows: $5^{\prime}$-CCA GGG TGC CAG GTA TAC AG-3' and $5^{\prime}-\mathrm{CC}-3 \mathrm{GCC}$ TTT TTA CAC TCC TCA AAA-3'. These primers were used to amplify a target sequence of 498 base pairs.

\section{Genotyping and PCR-RFLP}

PCR was performed in a $25-\mu \mathrm{L}$ reaction mixture containing $250 \mu \mathrm{M}$ of dNTP solution, 2.5 units of DNA Taq polymerase enzyme (Fermentas, Glen Burnie, MD, USA), $10 \times$ buffer, $1.5 \mathrm{mM} \mathrm{MgCl} 2,10 \mathrm{mM}$ Tris$\mathrm{HCl}, 50 \mathrm{mM} \mathrm{KCl}, 10$ pmol of each primer (CinnaGen Inc., Tehran, Iran), and $4 \mu \mathrm{L}$ of the extracted DNA. The thermal cycling conditions for replication of MTR were as follows: initial denaturation at $90^{\circ} \mathrm{C}$ for 4 
minutes, 34 cycles at $94^{\circ} \mathrm{C}$ for 1 minute, annealing for 1 minute at $56^{\circ} \mathrm{C}$, and extension for 1 minute at $73^{\circ} \mathrm{C}$, followed by a final extension at $72^{\circ} \mathrm{C}$ for 10 minutes. The PCR products were analyzed by electrophoresis in $1.2 \%(\mathrm{w} / \mathrm{v})$ agarose gel after DNA staining and visualized under ultraviolet transillumination. Then, the PCR product was digested for 16 hours at $37^{\circ} \mathrm{C}$ by the Haell enzyme. Finally, electrophoresis on $1.5 \%$ agarose gel was used to evaluate the enzyme efficiency. The results of the PCR products were statistically analyzed to assess the relationship between the point mutation in the 2756 region of the MTR gene with the occurrence of infertility in the study population.

\section{Data analysis}

The chi-square and Fisher tests were used to evaluate the association between polymorphisms in the 2756 region of the MTR gene and infertility in both groups (control and idiopathic male infertility groups). The statistical analysis was done separately and in combina-

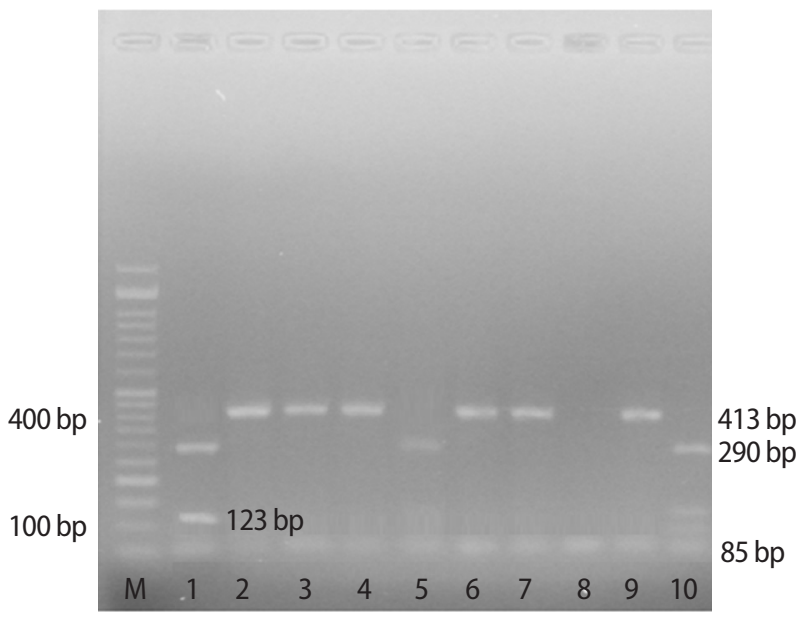

Figure 1. Genotyping MTR 2756A > G polymorphism by polymerase chain reaction and restriction fragment length polymorphism. Lane 1: marker $100 \mathrm{bp}$. Lane 2, 6, and 11: show 290, 123, and 85 bp band indicating the allele G. Lane 3, 4, 5, 7, 8, 9, and 10: show 413 and 85 bp bands indicating the allele $A$.

Table 1. Allele and genotype frequencies for MTR 2756A > G in infertile men and controls

\begin{tabular}{lccc}
\hline Variable & Infertility $(n=100)$ Control $(n=100)$ & Total $(n=200)$ \\
\hline Allele frequency & & & \\
A allele & $154(77)$ & $168(84)$ & $322(80.5)$ \\
G allele & $46(23)$ & $32(16)$ & $78(19.5)$ \\
Genotype & & & \\
AA & $59(59)$ & $70(70)$ & $129(64.5)$ \\
GA & $36(36)$ & $27(27)$ & $63(31.5)$ \\
GG & $5(5)$ & $3(3)$ & $8(4)$ \\
\hline
\end{tabular}

Values are presented as number (\%). tion. The results were reported as frequency and percentage, and $p$ values $<0.05$ were considered to indicate statistical significance. The obtained data were analyzed using IBM SPSS ver. 20.0 (IBM Corp., Armonk, NY, USA).

\section{Results}

The mean age of the participants was $35 \pm 5$ years. In our study, the MTR 2756A > G polymorphism was analyzed using a RFLP-PCR system in 100 infertile and 100 fertile men. The results of genotyping of the MTR 2756A > G polymorphism by PCR-RFLP are presented in Figure 1. The allele and genotype distributions of the $A 2756 \mathrm{G}$ polymorphism were $4 \%$, 31.5\%, 64.5\%, $19.5 \%$, and $80.5 \%$ for GG, GA, AA, G, and $A$, respectively. The frequencies of the $A$ and $G$ alleles were $77 \%$ and $23 \%$ in the infertile patients, and $84 \%$ and $16 \%$ in the control group. The frequency of the GG, GA, and AA genotypes was 5\%,36\%, and $59 \%$, respectively, in the infertile group and $3 \%, 27 \%$, and $70 \%$ in the control group (Table 1). The MTR $2756 \mathrm{~A}>\mathrm{G}$ polymorphism was present in both groups.

Table 2 presents the distribution of the MTR 2756A > G polymorphism in the infertile and control groups. There was no significant difference in the ratios of the $A A / G G, A A / G A$, and $G A / G G$ genotypes of the MTR $2756 \mathrm{~A}>\mathrm{G}$ polymorphism in either group $(p>0.05)$. No significant difference was found between the infertile and control groups in the frequency of the GG genotype compared with that of the $G A$ and $A A$ genotypes for the MTR 2756A > G polymorphism $(p=0.453)$. Furthermore, no significant difference was detected between the two groups in terms of the ratio of GA and GG genotypes versus $\mathrm{AA}$ genotypes $(p=0.113)$. In general, no significant difference was found between the two groups in the frequency of the MTR $2756 \mathrm{~A}>\mathrm{G}$ polymorphism in any genetic model.

\section{Discussion}

This study investigated the relationship between a single-nucleotide polymorphism in the MTR gene (MTR 2756A > G) and the risk for

Table 2. Genotype distribution analysis as a risk factor for male infertility compared to controls

\begin{tabular}{lcc}
\hline MTR 2756A > G (infertility case-control) & Odds ratio $(95 \% \mathrm{Cl})$ & $p$-value \\
\hline A vs. G & $1.568(0.772-3.187)$ & 0.212 \\
AA vs. GG & $2.004(0.460-8.744)$ & 0.346 \\
AA vs. GA & $1.560(0.848-2.869)$ & 0.151 \\
GA vs. GG & $1.286(0.282-5.860)$ & 0.745 \\
GA/AA vs. GG & $1.738(0.404-7.475)$ & 0.453 \\
AA vs. GG/GA & $0.623(0.347-1.120)$ & 0.113 \\
\hline
\end{tabular}

$\mathrm{Cl}$, confidence interval. 
idiopathic male infertility in men from the west and northwest of Iran. To the best of our knowledge, no study has been conducted of the MTR 2756A $>G$ polymorphism and its association with idiopathic male infertility in this.

MS is an enzyme that catalyzes the transfer of a methyl group from 5-methyltetrahydrofolate to homocysteine and methionine, resulting in tetrahydrofolate production. Furthermore, 5- and 10-methyltetrahydrofolate participate in DNA synthesis through the replacement of dUTP with dTTP [4].

In this study, the frequencies of $\mathrm{A}$ and $\mathrm{G}$ alleles were $77 \%$ and $23 \%$, respectively, in the infertile patients versus $84 \%$ and $16 \%$, respectively, in the control group. The frequency of the AA, GG, and GA genotypes was $59 \%, 5 \%$, and $36 \%$, respectively, in infertile subjects compared to $70 \%, 3 \%$, and $27 \%$, respectively, in the control group of healthy men.

The results obtained from our study indicate that the ratio of the AA and GG genotypes for the MTR 2756A > G polymorphism in patients with idiopathic infertility was not significantly different from that of the control group. The same result was obtained for the GG and GA genotypes. Furthermore, there was no statistically significant difference in the frequency of the $A$ allele between the infertile and control groups. The results of this study also showed no significant association between the GG genotype and idiopathic male infertility. Overall, the findings of this study indicate that there is no relationship between the MTR 2756A > G polymorphism and male infertility. In a study conducted by Kim et al. [17] on polymorphisms of MTR, a significant association was found between mutations of the MTR gene in the 2756 region and loss of pregnancy in women. In another study by Lee et al. [4] in South Korea on three common enzymes (MTHFR, MS, and MS reductase) involved in folate metabolism that play a key role in DNA synthesis and methylation reactions, a significant association was found between mutations of the MTR gene in the 2756 region and azoospermia in nonobstructive infertile men with no further chromosomal disorders.

Consistent with our findings, Weiner et al. [10], in a study conducted in Russia, stated that MTR gene mutations in the 2756 region did not have any significant relationship with azoospermia, although they found that an MTR gene mutation in the 2756 region was significantly associated with decreased serum level of progesterone. In a study by Kurzawski et al. [18] in Poland that investigated the relationship between genetic variations in folate-dependent enzymes and nonobstructive male infertility, no significant difference was found in genotype or allele frequency between infertile and healthy fertile men, and no relationship was found between MTR gene mutations and nonobstructive male infertility in the Polish population.

Conversely, in the study conducted by Gava et al. [19] in Brazil, idiopathic male infertility with nonobstructive azoospermia or severe oli- gozoospermia was significantly associated with the MTR 2756A $>G$ polymorphism ( $p=0.017$ ), although no statistically significant difference was found for the MTHFR 677 C > T polymorphism. Nevertheless, the statistical analysis did not suggest any relationship between the severe oligozoospermia group and the control group. Their findings suggested that the MTR $2756 \mathrm{~A}>\mathrm{G}$ polymorphism could be an important genetic predisposing factor for idiopathic infertility in Brazilian men.

Various studies in different populations have reported inconsistent results regarding this relationship. This inconsistency has also been seen for the other genes involved in the folate pathway. MTHFR and MTHFD play critical roles in DNA synthesis and remethylation $[4,10,14,20]$. Associations of polymorphisms of the genes encoding these enzymes with male infertility have also been investigated in several studies, with divergent results. Some studies reported that common polymorphisms in critical genes of the folate pathway were major risk factors for idiopathic male infertility [4,10,21-24], but other studies yielded the opposite results $[10,18,25]$.

In conclusion, the findings of the current study suggest that the MTR 2756A $>G$ polymorphism is not a predisposing factor for idiopathic infertility in Iranian men. However, more research on different populations is required to address the role of polymorphisms in different genes in idiopathic male infertility.

\section{Conflict of interest}

No potential conflict of interest relevant to this article was reported.

\section{Acknowledgments}

The authors are grateful to Mr. Mostaphzade for his technical assistance. And, the authors thank the Maragheh University of Medical Sciences and Qafqaz Fertility Center (a fertility clinic in Ardabil, Iran) for their cooperation and assistance in case identification.

\section{ORCID}

Asghar Tanoomand https://orcid.org/0000-0002-4488-8414 Abolfazl Hajibemani https://orcid.org/0000-0003-2181-4487

Beheshteh Abouhamzeh https://orcid.org/0000-0002-2424-5980

\section{Author contributions}

Conceptualization: all authors. Data curation \& Formal analysis: AT, AH. Funding acquisition: AH, BA. Methodology, Project administration, Visualization, Writing - original draft, review \& editing: all authors. 


\section{References}

1. Speroff L, Class RH, Kase NG. Clinical gynecologic endocrinology and infertility. 6th ed. Philadelphia: Lippincott Williams \& Wilkins; 1999.

2. Ebisch IM, Pierik FH, DE Jong FH, Thomas CM, Steegers-Theunissen RP. Does folic acid and zinc sulphate intervention affect endocrine parameters and sperm characteristics in men? Int J Androl 2006;29:339-45.

3. Shefi S, Turek PJ. Definition and current evaluation of subfertile men. Int Braz J Urol 2006;32:385-97.

4. Lee HC, Jeong YM, Lee SH, Cha KY, Song SH, Kim NK, et al. Association study of four polymorphisms in three folate-related enzyme genes with non-obstructive male infertility. Hum Reprod 2006;21:3162-70.

5. Maclean JA 2nd, Wilkinson MF. Gene regulation in spermatogenesis. Curr Top Dev Biol 2005;71:131-97.

6. Singh K, Jaiswal D. One-carbon metabolism, spermatogenesis, and male infertility. Reprod Sci 2013;20:622-30.

7. Crha I, Kralikova M, Melounova J, Ventruba P, Zakova J, Beharka R, et al. Seminal plasma homocysteine, folate and cobalamin in men with obstructive and non-obstructive azoospermia. J Assist Reprod Genet 2010;27:533-8.

8. Boxmeer JC, Smit M, Weber RF, Lindemans J, Romijn JC, Eijkemans MJ, et al. Seminal plasma cobalamin significantly correlates with sperm concentration in men undergoing IVF or ICSI procedures. J Androl 2007;28:521-7.

9. Lewis $S E$, Aitken RJ. DNA damage to spermatozoa has impacts on fertilization and pregnancy. Cell Tissue Res 2005;322:33-41.

10. Weiner AS, Boyarskikh UA, Voronina EN, Tupikin AE, Korolkova OV, Morozov IV, et al. Polymorphisms in folate-metabolizing genes and risk of idiopathic male infertility: a study on a Russian population and a meta-analysis. Fertil Steril 2014;101:87-94.

11. Nuti F, Krausz C. Gene polymorphisms/mutations relevant to abnormal spermatogenesis. Reprod Biomed Online 2008;16:50413.

12. Bentivoglio G, Melica F, Cristoforoni P. Folinic acid in the treatment of human male infertility. Fertil Steril 1993;60:698-701.

13. Wong WY, Merkus HM, Thomas CM, Menkveld R, Zielhuis GA, Steegers-Theunissen RP. Effects of folic acid and zinc sulfate on male factor subfertility: a double-blind, randomized, placebocontrolled trial. Fertil Steril 2002;77:491-8.

14. Hum DW, Bell AW, Rozen R, MacKenzie RE. Primary structure of a human trifunctional enzyme: isolation of a cDNA encoding methylenetetrahydrofolate dehydrogenase-methenyltetrahydrofolate cyclohydrolase-formyltetrahydrofolate synthetase. J Biol Chem 1988;263:15946-50.

15. Parle-McDermott A, Mills JL, Kirke PN, Cox C, Signore CC, Kirke S, et al. MTHFD1 R653Q polymorphism is a maternal genetic risk factor for severe abruptio placentae. Am J Med Genet A 2005; 132A:365-8.

16. Direkvand-Moghadam A, Delpisheh A, Khosravi A. Epidemiology of female infertility; a review of literature. Biosci Biotechnol Res Asia 2013;10:559-67.

17. Kim JH, Jeon YJ, Lee BE, Kang H, Shin JE, Choi DH, et al. Association of methionine synthase and thymidylate synthase genetic polymorphisms with idiopathic recurrent pregnancy loss. Fertil Steril 2013;99:1674-80.

18. Kurzawski M, Wajda A, Malinowski D, Kazienko A, Kurzawa R, Drozdzik M. Association study of folate-related enzymes (MTHFR, MTR, MTRR) genetic variants with non-obstructive male infertility in a Polish population. Genet Mol Biol 2015;38:42-7.

19. Gava MM, Kayaki EA, Bianco B, Teles JS, Christofolini DM, Pompeo AC, et al. Polymorphisms in folate-related enzyme genes in idiopathic infertile Brazilian men. Reprod Sci 2011;18:1267-72.

20. Carrell DT. Epigenetics of the male gamete. Fertil Steril 2012; 97:267-74.

21. Bezold G, Lange M, Peter RU. Homozygous methylenetetrahydrofolate reductase C677T mutation and male infertility. N Engl J Med 2001;344:1172-3.

22. Popp RA, Farcas MF, Trifa AP, Militaru MS, Crisan TO, Pop IV. The methylenetetrahydrofolate dehydrogenase (MTHFD 1) gene G1958A polymorphism and idiopathic male infertility in a Romanian population group. Clujul Med 2012;85:54-8.

23. Saleh RA, Agarwal A, Nada EA, El-Tonsy MH, Sharma RK, Meyer A, et al. Negative effects of increased sperm DNA damage in relation to seminal oxidative stress in men with idiopathic and male factor infertility. Fertil Steril 2003;79 Suppl 3:1597-605.

24. Khaki AA, Tanoomand A, Hajibemani A, Abouhamzeh B. Detection of polymorphisms in MTHFD1 G1958A and its possible association with idiopathic male infertility. Urol J 2019 Mar 18 [Epub]. http://dx.doi.org/10.22037/uj.v0i0.4647.

25. Balkan M, Atar M, Erdal ME, Rustemoglu A, Yildiz I, Gunesacar R, et al. Possible association of FAS and FASLG polymorphisms with the risk of idiopathic azoospermia in southeast Turkey. Genet Test Mol Biomarkers 2014;18:383-8. 